\title{
Gobierno abierto en la Comunidad Valenciana
}

MEI

II, vol. 4

$\mathrm{n}^{0} 7$

\author{
Vicent Giménez Chornet ${ }^{1}$, Miguel Carlos Muñoz Feliu${ }^{1}$, \\ Daniel Català Pérez ${ }^{1}$, Natividad Romina Masciotta ${ }^{1}$ \\ ${ }^{1}$ Universidad Politécnica de Valencia
}

\section{Resumen}

El Gobierno Abierto es uno de los retos de la transparencia al permitir difundir la información de la actividad y operaciones de los gobernantes locales, permitiendo que estos puedan ser supervisados por la comunidad de vecinos. En el presente artículo se analiza la implantación del Gobierno Abierto en los municipios de la Comunidad Valenciana. Se han categorizado los temas susceptibles de difundir en la web municipal, y tras su análisis estadístico se demuestra el bajo porcentaje de municipios que alcanzan a publicar la mayor parte de las categorías.

Palabras clave:

Gobierno Abierto; Transparencia; Información pública; Responsabilidad política

Open government in Valencia

Abstract

Open Government is one of the challenges of transparency by allowing information to spread the business and operations of local governments, allowing these can be supervised by the community of neighbors. In this article the implementation of the Open Government in the municipalities of Valencia is analyzed. Were categorized the topics susceptible to spread on the municipal website, and after statistical analysis shows the low percentage of municipalities which reach to publish most of the categories.

Keywords

Open Government, Transparency, Public Information, Policy responsibility

\section{1.- Introducción}

Utilizamos el concepto de gobierno abierto para referirnos a la rendición de cuentas y al acceso a la información de las actividades realizadas por los gobiernos públicos, elegidos democráticamente por los ciudadanos, como consecuencia de su gestión y desarrollo de políticas. Los gobernantes públicos son personas que representan a los ciudadanos, que no tienen en propiedad el patrimonio y caudales públicos, sino que lo gestionan como delegados de a quienes representan, por un tiempo limitado (por el que han sido elegidos), que rinden cuentas a los organismos legalmente establecidos (tribunales de cuentas, y en concreto en la Comunidad Valenciana a la Sindicatura de Cuentas) y que toman decisiones (plenos de los ayuntamientos, contratación de servicios, etc.) 
como representantes de la ciudadanía. Aunque se reconoce que la población tienen ciertos derechos a conocer dicha información, pocos gobiernos difunden sus actos, así como los resultados de la gestión de las cuentas públicas, a sus electores haciendo uso de las TIC, especialmente de la Web.

A mediados de los 90, con la irrupción de Internet, ya se planteó que ésta era una herramienta idónea para que la información oficial que afectaba a la ciudadanía se pudiese difundir. Una propuesta surgió en Gran Bretaña, mediante la intervención de las bibliotecas, bajo el concepto de New Library, que permitiría una nueva era de cohesión social a través de la participación pública dentro de los límites geográficos de una comunidad y con un propósito común, pudiendo interesar la información relacionada con los servicios locales (educación, salud, servicios sociales, etc.), la información sobre la actuación local y la implementación del presupuesto, información sobre el desarrollo local y regional, publicaciones gubernamentales en línea, publicaciones de procedimientos y de normas jurídicas, e incluso difusión del partido político y sus políticas (Chandler, Helen E., 1998).

Cuando nos referimos a gobierno abierto (los gobernantes ofrecen información de sus acciones) no nos referimos a gobierno participativo o e-government, que se centra en una interacción entre el gobierno y los ciudadanos, permitiendo que estos realicen aportaciones (tanto de gestión como de consulta), favoreciendo un aumento de confianza en el gobierno como consecuencia de esa interacción (Reddick, Christopher G., 2011). Gobierno abierto tiene cierta relación con la transparencia, pero la transparencia va más allá, mientras el gobierno abierto debe ser proactivo y ofrecer información de sus actuaciones, la trasparencia en la gestión pública es la posibilidad de que los ciudadanos consigan acceder a cualquier tipo de información, registrada en cualquier soporte, generada por las entidades en el desarrollo de sus funciones (Giménez-Chornet, Vicent, 2012). Actualmente sería muy costoso e inviable poner toda la información que existe en los archivos públicos en Internet, pero si es posible que los gobiernos garanticen su acceso a todos aquellos que necesiten cualquier tipo de información registrada en los actos administrativos, limitándose el acceso sólo en aquellos preceptos establecidos en las leyes. Gobierno abierto tampoco implica el concepto reutilización de la información, según los criterios de la Directiva 2003/98/ CE del Parlamento Europeo y del Consejo, entendiendo que la "reutilización de documentos del sector público debe permitir, entre otras cosas, a las empresas europeas aprovechar su potencial y contribuir al crecimiento económico y a la creación de empleo" (Unión Europea, 2003). Estos documentos del sector público que puedan ser de interés para su reutilización por la ciudadanía están siendo divulgados en España en el portal Web http://datos.gob.es/datos/.

Ariel Vercelli (2010) plantea que el gobierno abierto se relaciona con la disponibilidad de datos y las informaciones públicas, planteándose la cuestión de si son bienes privativos, públicos o comunes y qué tipo de acceso y disponibilidad tienen los ciudadanos. Las administraciones públicas conservan abundantes documentos relacionados con los actos que ejercen los representantes políticos (decisiones de gobierno) como su implantación por el personal administrativo (contratos para suministrar servicios con dinero público, contabilidad, inspecciones, etc.) a los que el 
ciudadano tiene derecho a conocer. El objetivo del presente estudio es conocer el grado de implantación de gobierno abierto en la administración local, la más cercana a los ciudadanos, y qué aspectos de las actividades de gobierno son más difundidas a la comunidad, mediante la utilización de la Web. Compartimos la opinión de Sylvia Kierkegaard (2008) que en el corazón de toda democracia es importante la participación activa de las personas en el gobierno que toman decisiones que afectan a su vida activa, lo que implica la posibilidad real de consultar o adquirir información oportuna detallada electrónicamente, de forma gratuita, sin barreras y sin ahogarse en la migraña de localizar datos en una gran variedad de ellos insertos en un sistema complejo.

\section{2.-Metodología}

El presente artículo es consecuencia del proyecto "Govern Obert a la Comunitat Valenciana" (http://governobertcv.es/), llevado a cabo por los alumnos de la asignatura optativa transversal Gestión del Documento Electrónico, del tercer curso del Grado en Gestión y Administración Pública ${ }^{1}$, impartido en la Facultad de Administración y Dirección de Empresas de la Universitat Politècnica de València. Dicho proyecto se estableció al inicio del curso 2012/2013, por consenso, entre los profesores y el alumnado de la asignatura, como la actividad o trabajo conjunto a realizar en las 10 sesiones de prácticas de laboratorio, en sustitución de las clásicas prácticas individuales. Más allá del interés que en materia docente pueda tener, y sin duda tiene, la implementación de instrumentos formativos prácticos en grupo como el que se describirá, el principal motivo que provocó el interés de aprovechar el trabajo realizado, fue el hecho de comprobar que se había conseguido una base de datos con una información actualizada, relevante y muy completa. Con una revisión exhaustiva del trabajo hecho, el tratamiento oportuno de los datos y su posterior análisis e interpretación, esa base de datos podría mostrar una imagen panorámica de la situación actual de la administración local valenciana en la red.

El proyecto "Govern Obert a la Comunitat Valenciana" consistió, inicialmente, en la creación de un portal web a través de la cual, cualquier persona interesada, pudiera acceder a la información y documentación de gestión municipal que los ayuntamientos de los municipios de la Comunitat Valenciana ponen a disposición de los ciudadanos. Para el sitio web se ha implantado el software WordPress, por las siguientes ventajas: es un CMS (Content Management System), utiliza bases de datos que se ejecutan con MySQL, y es abierto y gratuito. Aunque está diseñado preferentemente para la creación de blogs, se le ha suprimido las funcionalidades de participación de los visitantes (funcionalidades web 2.0), dejando el sitio como una simple web. Para la indización individualizada se ha recurrido a la creación de etiquetas, para las poblaciones y demarcaciones locales, y la creación de categorías para los temas de gobierno abierto. Gracias al sistema de etiquetas y categorías, los enlaces son fácilmente accesibles mediante búsquedas simples por población (la nomenclatura usada en el sitio web del proyecto respecto de los topónimos ha sido la oficial, ya sea esta en castellano, valenciano o bilingüe), comarca, provincia o tipo de 
información buscada, de forma que encontraremos toda la información o documentación ofrecida para un municipio, una comarca o una provincia, o por otro lado, todas las poblaciones que ofrecen información o documentación dentro de una determinada categoría Con ello hemos tratado de facilitar el acercamiento a toda esa información, creando un acceso único a la misma a través de un listado de enlaces directos alojados en el mencionado sitio web.

A medida que se iba realizando el oportuno vaciado de información de cada una de las páginas de los ayuntamientos valencianos, se comprobaban las diferencias existentes entre poblaciones y con ello, el potencial informativo que tenían los datos que se iban recogiendo. El sitio web del proyecto está, lógicamente, activo y es plenamente accesible, pues es sustento de toda la información vertida en el presente artículo. Precisamente por ello, conscientes de la importancia que este hecho tiene, y como ya se ha comentado, los autores y continuadores del proyecto inicial hemos llevado a cabo una exhaustiva revisión del portal y de la información y los enlaces allí mostrados.

El trabajo de revisión y vaciado de las páginas web de los ayuntamientos se realizó durante las sesiones de prácticas de laboratorio de los alumnos, que fueron un total de 10 sesiones de 2 horas cada una. Durante esas 10 sesiones de prácticas, el trabajo consistió en navegar por las webs municipales recabando la información de los temas de gobierno abierto detectados, e incorporando el enlace al sitio web del proyecto, mediante su respectiva alta como entrada, e indizando cada entrada por categorías (los temas) y por etiquetas (la entidad local). Los 542 municipios de la Comunitat Valenciana se repartieron entre los 9 alumnos del grupo para realizar el "trabajo de campo" de vaciado de la información y documentación. El reparto se procuró realizar por provincias y por comarcas de forma que dos personas se ocuparon de la provincia de Alicante, dos más de la provincia de Castellón y las cinco restantes de la de Valencia, como provincia con más municipios.

Un reto metodológico ha sido encontrar la información entre una gran variedad y tipología de diseños de portales webs, además de identificar su dominio legítimo. Si bien es cierto, que en las tres provincias de la Comunitat Valenciana y generalmente, gracias a los planes de modernización impulsados por las Diputaciones Provinciales (unas más que otras, como se verá), existe un gran número de localidades, normalmente las de menor tamaño, con diseños web similares, lo normal es encontrarse con portales de todo tipo: desde los más atractivos y funcionales, a páginas web con graves problemas de navegabilidad e incluso accesibilidad.

Las categorías definidas para la clasificación de la información ofrecida por los ayuntamientos son las que se recogen en la primera columna de la tabla 1. Para el tratamiento y análisis de los datos en el presente artículo, se han efectuado algunas pequeñas modificaciones, resultando por tanto, las categorías mostradas en la segunda columna de la misma tabla. Revisamos a continuación que se ha tenido en cuenta a la hora de definir cada categoría y que tipo de información o documentación se ha incluido dentro de cada una. 
MEI, II, Vol. 4, n7 , pág. 133

\begin{tabular}{|l|l|}
\hline CATEGORIAS EN LA WEB & CATEGORÍAS SIMPLIFICADAS. \\
\hline Bandos & Bandos \\
\hline Boletines & Boletines \\
\hline Contratación de servicios & Contratación de servicios \\
\hline Convocatorias públicas & Juntas de Gobierno Local \\
\hline Estatutos & Ordenanzas \\
\hline Juntas de Gobierno Local & Planes de urbanismo \\
\hline Ordenanzas & Plenos \\
\hline Planes de urbanismo & Presupuestos \\
\hline Plenos & Retribuciones \\
\hline Presupuestos & Estatutos - Reglamentos \\
\hline Reglamentos & \\
\hline Retribuciones & \\
\hline
\end{tabular}

Tabla 1: Categorías definidas

La categoría de Bandos agrupa no sólo a este tipo de mandatos o manifestaciones municipales sino que además se incluyen también los edictos e incluso ciertos anuncios municipales. La corriente confusión que existe a la hora de diferenciar entre bandos, edictos y anuncios, provoca que a un mismo tipo de documento se le llame de diferente forma en cada ayuntamiento, con lo que establecer una distinción entre ellos era tarea harto complicada (el bando es el mandato de obligatoria y general observancia y se distingue de los edictos en que éstos se dictan para promover la audiencia de todos o sólo de una parte del vecindario). En un gran número de casos, la información incluida dentro de la categoría Bandos se corresponde con la información publicada en la web municipal dentro de la sección del Tablón de Anuncios.

En cuanto a Boletines, lógicamente, lo que se ha incluido dentro de esta categoría ha sido la publicación de boletines municipales (BIM, Boletín de Información Municipal, en muchos casos), que incluyan información de gestión municipal. Es decir, lo que no se han incluido son publicaciones que recojan únicamente una guía de ocio o de actividades, sino que se ha intentado ir un paso más allá, buscando aquellos boletines que verdaderamente ofrezcan información interna del propio ayuntamiento al ciudadano. Existe algún caso en que la publicación del boletín es directamente on-line, pero por lo general se trata de archivos descargables en formato digital que a su vez se publican normalmente también en papel.

La categoría de Contratación de Servicios es una de las que, tal vez menos ha costado llenar de contenido, pues lógicamente el Perfil del Contratante de cada portal municipal es el que debería incluir toda la información o documentación de este tipo. Y decimos debería, porque en algún caso se ha encontrado el Perfil del Contratante vacío de contenido y la información sobre contratación en cualquier otra sección (afortunadamente pocos casos). Mención aparte merece la calidad de la información publicada en el citado Perfil del Contratante. No se han tenido en cuenta las webs de ayuntamientos que únicamente publicaban el anuncio de licitación, sino que se ha 
buscado aquellos ayuntamientos que publicaban al menos, la adjudicación de los contratos y si además aparecía más documentación del procedimiento de contratación (pliegos, bases, composición de la mesa de contratación, ofertas, apertura de sobres, etc.) mucho mejor. En este sentido, cabe destacar que en algunos casos, en la elaboración del presente estudio, se ha sido menos exigente con los ayuntamientos respecto a la publicación de determinada información y documentación, que la propia legalidad.

Dentro de la categoría de Juntas de Gobierno Local y Plenos, la información incluida han sido las actas, completas o al menos en extracto, pero no se han tenido en cuenta aquellos ayuntamientos que únicamente publican las convocatorias, pues estos documentos no aportan ningún tipo de información de gestión municipal. En algunos casos, las actas de las juntas de gobierno y de los plenos aparecen publicadas dentro de la misma sección sin distinguir unas de otras, por lo que comparten el mismo enlace. Es interesante destacar como existen ya algunos ayuntamientos, generalmente los de mayor tamaño y por tanto con más medios, que empiezan a aprovechar más decididamente las oportunidades que ofrecen las TIC, ofreciendo retransmisiones en directo de los Plenos y subiéndolos a la web para su posterior visionado.

La categoría de Ordenanzas no ha presentado excesivos problemas a la hora de definir su contenido pues en todos los ayuntamientos quedan bien definidas las publicaciones referidas a las ordenanzas. El problema ha surgido a la hora de localizarlas dentro de cada una de las páginas web, pues aunque existen muchos portales en los que existe una sección definida y claramente accesible sobre normativa municipal que las aglutina todas, en otros tantos casos, esta normativa está publicada por secciones o áreas (ordenanzas fiscales, ordenanzas urbanísticas, etc.) con la dispersión que ello supone.

La categoría de Urbanismo es otra en la que encontrar información o documentación en aquellas webs que la tenían publicada no ha sido excesivamente difícil, aunque sí el hecho de considerar que esa información cumplía o no con los requisitos para incluirla en nuestro estudio. Los planes urbanísticos totales o parciales, en vigor o en período de información pública siempre se han tenido en cuenta, pero además se han encontrado multitud de documentos de toda índole que prácticamente se han tenido que revisar uno a uno para comprobar su interés. Cabe decir, en honor a la verdad, que generalmente, aquellos ayuntamientos con información urbanística on-line, presentan algún tipo de información de interés.

En cuanto al aspecto económico se han distinguido dos categorías diferentes, la de Presupuestos y la de Retribuciones. Respecto a esta última, muy pocas poblaciones presentan información en abierto referida a las retribuciones económicas de los miembros de la corporación municipal (que es lo que se buscaba en esta categoría), aunque la mayoría que lo hacen, muestran una información bastante completa. En cuanto a los presupuestos municipales, se ha incluido a aquellos ayuntamientos que aunque no presenten una información completa y exhaustiva de sus presupuestos, si publiquen al menos resúmenes de los mismos o algún tipo de documentación referida a la gestión y contabilidad presupuestaria. 
Finalmente, las categorías de Estatutos y Reglamentos que en la web del proyecto aparecen diferenciadas, para el análisis de los datos se han unido en una sola, pues en la práctica totalidad de las páginas webs revisadas, con información de este tipo, se confunden los unos con los otros, aún existiendo una diferencia clara entre ellos.

Hay un aspecto importante a destacar que afecta sobre todo los portales de ayuntamientos de poblaciones pequeñas. La falta de recursos de algunos de estos ayuntamientos hace que a la hora de confeccionar sus páginas web y llenarlas de contenido recurran a planes de modernización impulsados por las Diputaciones Provinciales (influyendo este hecho en los resultados del análisis efectuado en este estudio). Esto conlleva que en algunos casos, como ocurre principalmente en los municipios pequeños de la provincia de Alicante, la página web del ayuntamiento en cuestión redirija (mediante un enlace) al internauta a alguna base de datos de la propia Diputación, que contiene información referente a presupuestos, ordenanzas o urbanismo, por ejemplo. Cuando el enlace en cuestión funciona sin problemas y lleva directamente a la información buscada sin tener que dar ningún paso más, se ha considerado esta información como contenida en la propia web del ayuntamiento. De hecho, existen ejemplos de portales en los que encontrar determinada información es mucho más complicado, teniendo que hacer infinidad de clics, además de que dicha información puede no estar presentada con la claridad que lo hace en este caso, la Diputación de Alicante.

Para no ser redundantes detallamos que la fuente de todos los gráficos es una hoja Excel, resultado de un proceso de elaboración realizado en el mes de diciembre de 2013 a partir de la captura de la información del sitio web Govern Obert a la Comunitat Valenciana, disponible en http://governobertcv.es/,. La hoja de cálculo ha permitido el procesamiento de los datos y le creación de los gráficos.

\section{3.- Análisis de los datos.}

\section{1-Resultados globales.}

De los 542 municipios de la Comunitat Valenciana recogidos en el sitio web Govern Obert a la Comunitat Valenciana, 480 de los mismos ofrecen algún tipo de dato abierto a través de sus portales web. Ello representa un $89 \%$ del total. Sólo 62 municipios, un $11 \%$ del total, no incluyen ningún tipo de dato abierto en sus sedes web, bien porque las propias sedes electrónicas no existan o porque la información que recojan dichas sedes no contengan ninguno de los tipos de datos analizados en este estudio (Fig. 1). 


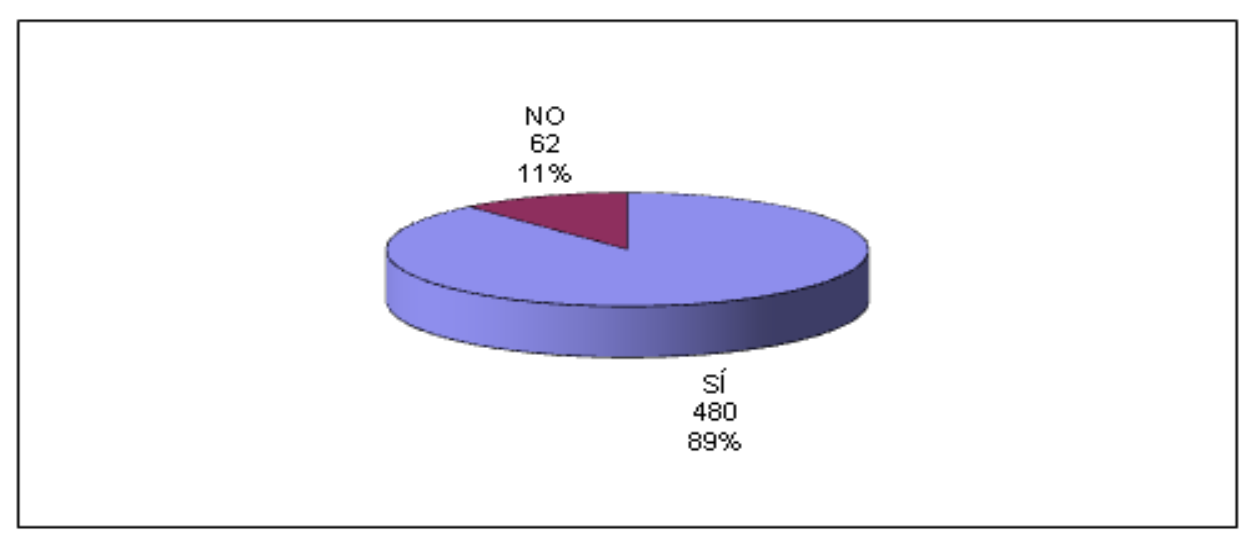

Fig. 1. Datos abiertos en los municipios de la Comunitat Valenciana (2013)

Ahora bien, no todos los ayuntamientos ofrecen datos abiertos de la misma naturaleza. Tal como puede observarse en la Figura 2, el nivel de transparencia varía enormemente de una a otra categoría analizada. Así, las ordenanzas, normativa dictada por los ayuntamientos en el ejercicio de sus competencias, están presentes en 339 de las sedes web analizadas, que representan un 63\% del total de los municipios valencianos.

En el otro extremo se sitúan las juntas de gobierno o las retribuciones. Sólo 36 municipios (un $7 \%$ del total) ofrecen datos abiertos relativos a las juntas de gobierno, organismo que, en la práctica, es el encargado de tomar todas aquellas decisiones que no deban pasar por imperativo legal por el pleno.

Peor aún es el caso de las retribuciones que sólo son ofrecen en 12 de estas sedes web (un $2 \%$ del total). Esta bajísima cifra contrasta con la fuerte presión popular para democratizar la vida pública y luchar contra la corrupción (por ejemplo, en el Movimiento del $15 \mathrm{M}$ ), que se ha reflejado en los últimos años en el anuncio de la publicitación de ingresos y propiedades por parte de diputados y otros responsables políticos. Una tendencia que no parece alcanzar a la administración local valenciana, a tenor de los resultados obtenidos.

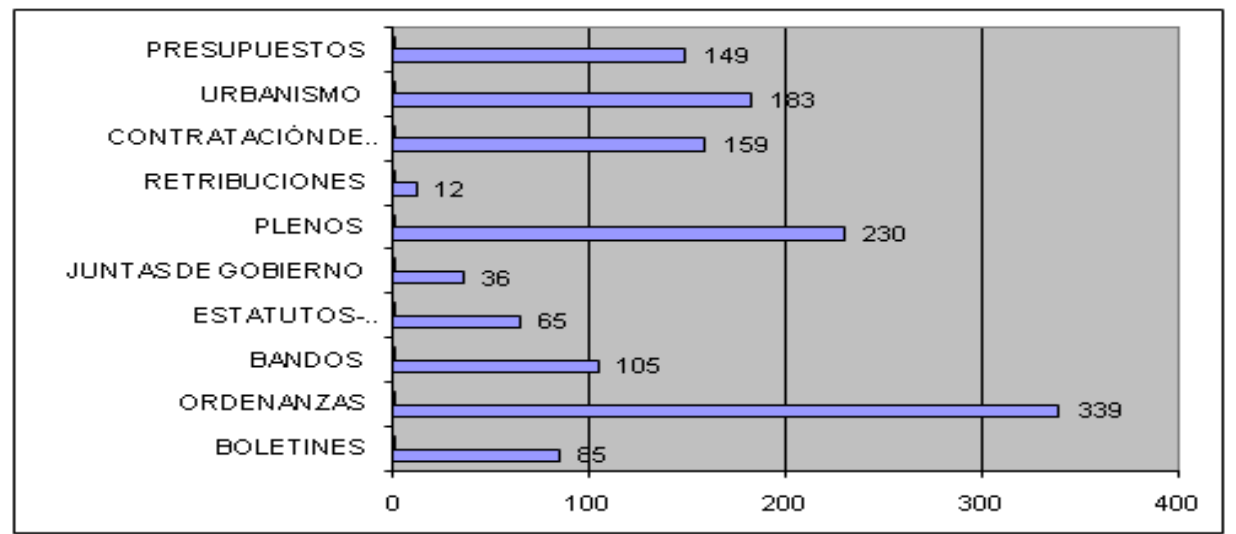

Fig. 2. Distribución por tipologías de datos abiertos en los municipios de la comunitat valenciana (2013) 


\section{2.-Resultados por provincia}

Se ha revisado la existencia de datos abiertos en las páginas de internet de los municipios valencianos en su globalidad, pero si desagregamos la información por provincias y a su vez, por categorías, se pueden observar los siguientes resultados.

En principio podría parecer lógico que la provincia de Valencia, la mayor de las tres en número de municipios y en población total, apareciera como la provincia con mayor cantidad de ayuntamientos con datos en abierto en internet, pero no es así como observamos en la figura 3. El porcentaje de municipios con datos abiertos en la provincia de Valencia es del $90 \%$, un punto por encima del total de la Comunitat Valenciana, pero es la provincia de Alicante la que presenta un mejor porcentaje con un $94 \%$. Lejos queda la provincia de Castellón con un $79 \%$, a 15 puntos de la de Alicante y 10 del total de la Comunitat.

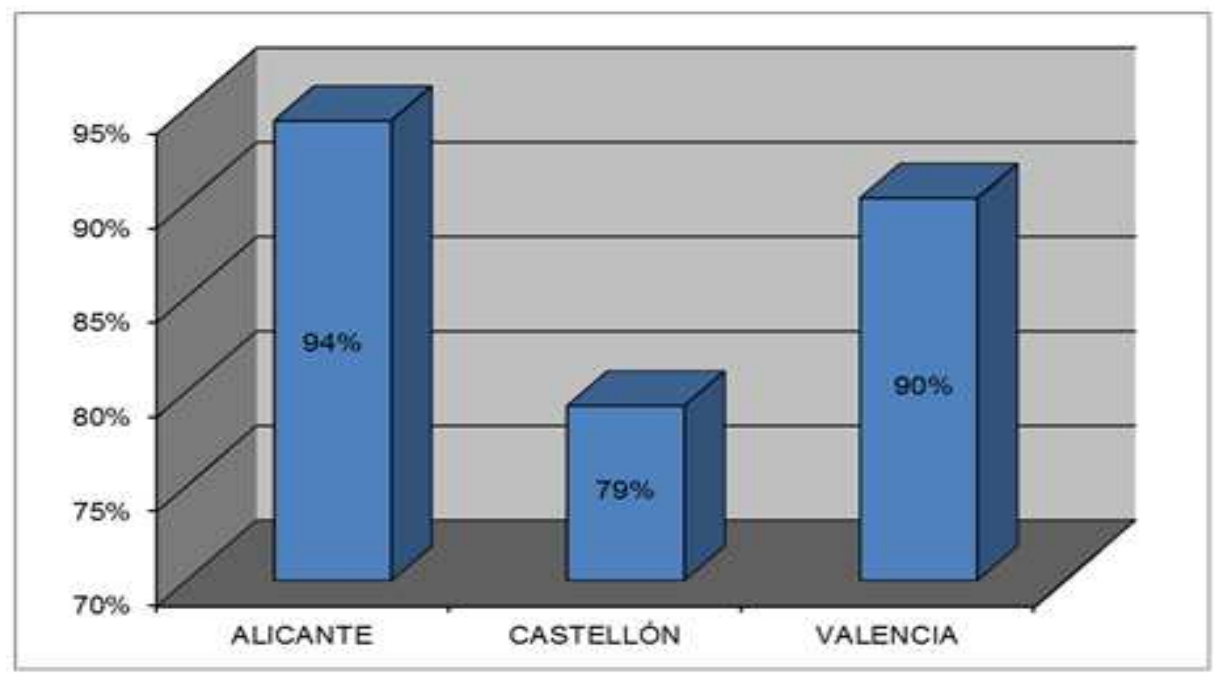

Fig. 3. Datos abiertos en los municipios de la comunitat valenciana por provincias

Por categorías, vemos en la figura 4 que la provincia de Alicante se sitúa con el porcentaje más alto de poblaciones con datos abiertos en todas ellas excepto en una. Es concretamente en la categoría de Boletines en la única que la provincia de Valencia es superior al resto y además de una forma bastante clara, con un $26 \%$ frente al pobre 8\% de Alicante o el todavía peor 2\% de Castellón.

Existen cuatro categorías en las que Castellón es superior a Valencia en porcentaje de poblaciones con datos abiertos, siempre por detrás de Alicante, que son Presupuestos, Urbanismo, Juntas de Gobierno y Estatutos-Reglamentos, aunque por un estrecho margen. En Retribuciones, que presenta porcentajes muy bajos en cualquier caso, se observa que la provincia de Castellón no cuenta con ninguna población con datos abiertos. 
En la categoría de plenos, vemos que las tres provincias presentan unos porcentajes que, aunque mantienen a Alicante en primer lugar, Valencia en segundo y Castellón en tercera posición, no presentan apenas diferencias. Es la única categoría en que se da esta circunstancia. De hecho, existen tres categorías en las que la diferencia de la provincia de Alicante respecto de las otras es muy grande y son precisamente tres categorías que junto a la de Plenos, presentaban un mayor número de poblaciones con datos en abierto en el conjunto de la Comunitat Valenciana: Ordenanzas, Presupuestos y Urbanismo.

En Ordenanzas, el 82\% de Alicante es muy superior al 57\% de Valencia y el 53\% de Castellón, al igual que ocurre en Urbanismo, donde Alicante con un 48\% supera en un $18 \%$ a Castellón y en un $20 \%$ a Valencia. Pero es en Presupuestos donde las diferencias son mayores, pues Alicante con un 56\%, prácticamente triplica el $19 \%$ de Castellón, algo que sí que hace con el 17\% de Valencia.

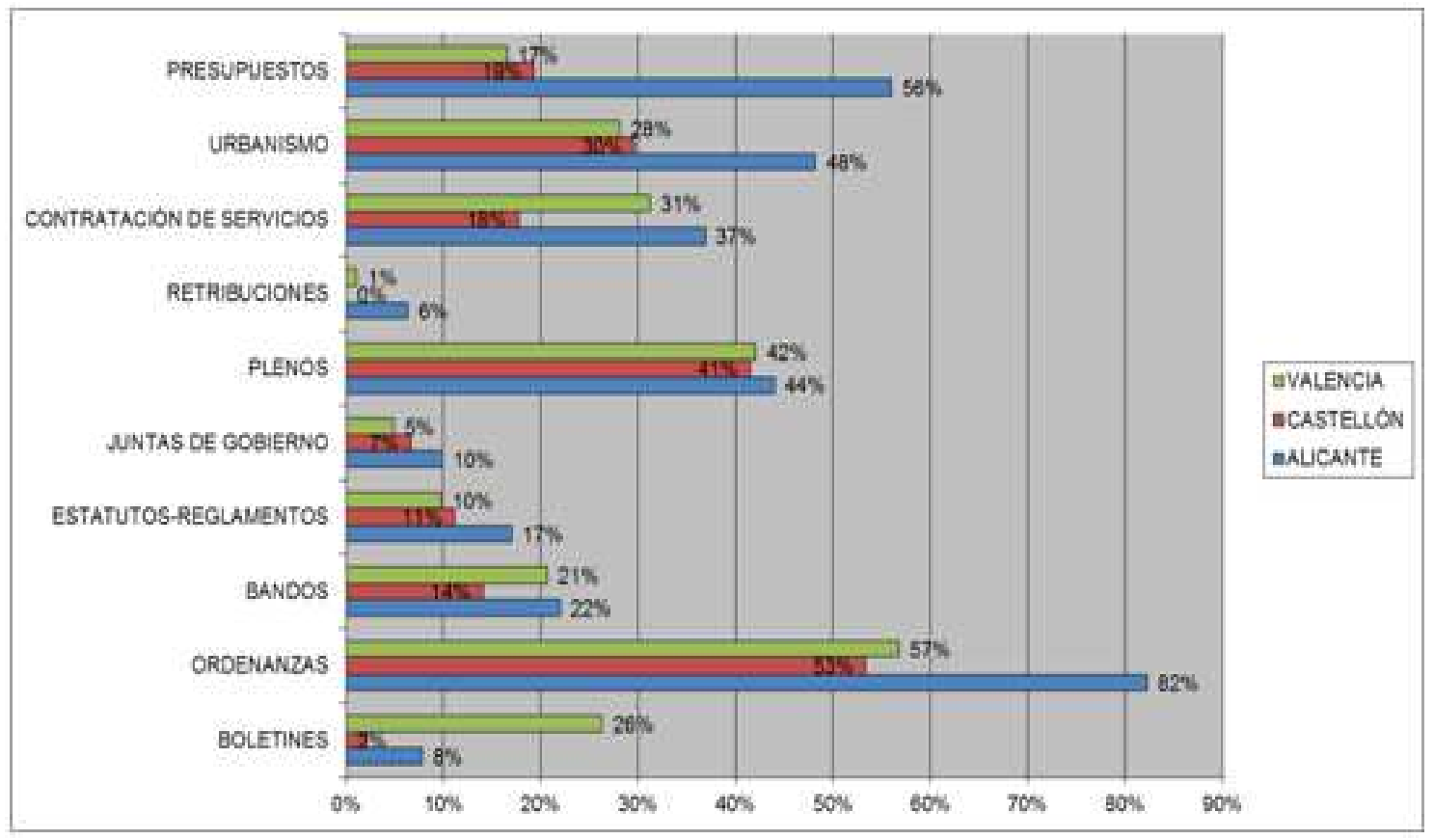

Fig. 4. Datos abiertos en los municipios de la comunitat valenciana por provincias y por categorías

Llegados a este punto podemos comprobar algo que ya se apuntaba cuando se explicó la metodología seguida en el presente estudio. Se hablaba de la influencia de los planes de modernización para la administración local impulsados por las Diputaciones Provinciales. Esta influencia, en el caso de la provincia de Alicante es muy alta. La Diputación de Alicante ha desarrollado las páginas web de muchos municipios alicantinos (los de menor tamaño y con menos recursos) dotando a dichas páginas web, obviamente de un diseño uniforme y de un contenido más o menos similar, con unas secciones más o menos fijas en todos los casos. 
La pestaña de presupuestos, urbanismo, ordenanzas y plenos está presente a casi todos los portales de estos ayuntamientos pequeños, y como ya se comentó, generalmente enlazan directamente con las bases de datos de la propia Diputación que ofrecen una información mucho más detallada y clara que la que tal vez podrían ofrecer los ayuntamientos por sus propios medios. Aunque las Diputaciones Provinciales de Valencia y Castellón también impulsan planes de modernización y desarrollo de la administración local, en el sentido descrito sus servicios no parecen tan completos como el de la Diputación de Alicante y esto tiene una influencia directa en los resultados obtenidos en este estudio.

\section{3.-Distribución por población.}

Desde mediados del siglo XX se ha producido una continuada concentración de la población en la periferia peninsular, especialmente en la costa del mediterráneo debido el desarrollo económico y turístico, y en consecuencia la Comunidad Valenciana presenta altas tasas de densidad de población con respecto al resto de la península (Franch Auladell, X.; Marti-Henneberg, Jordi; Puig-Farré, J., 2013), y sin embargo destaca la dispersión de dicha población en muchos municipios. La Comunidad Valenciana, territorio heredero en gran parte del antiguo Reino de Valencia, está dividido oficialmente en 3 provincias y 542 municipios, aunque a lo largo de la historia ha tenido distintas fronteras y demarcaciones (Membrado Tena, J. C., 2013). La peculiaridad de la abundancia de municipios está causada por la jurisdicción alfonsina, de época medieval, que ha determinado la independencia de los pequeños municipios en el transito del Antiguo Régimen, y disolución del régimen señorial, al periodo constitucional. Aunque entre el siglo XIX y XX ha crecido en población, aún en la actualidad existe un gran número de pequeños municipios. Hay 136 municipios menores de quinientos habitantes, o 215 menores de mil habitantes, es decir, casi el 40\% de los municipios valencianos.

De forma global la primera cuestión a resolver es poder constatar, por el tamaño del municipio, cuantos ofrecen datos abiertos, y poder esclarecer qué franja, por el número de habitantes, es más proclive a ofrecer estos datos abiertos.

\begin{tabular}{|l|c|}
\hline \multicolumn{2}{|c|}{ Datos abiertos por franjas de tamaño del municipio } \\
\hline Franja de municipios por habitantes & $\begin{array}{c}\text { Porcentaje de municipios con datos } \\
\text { abiertos }\end{array}$ \\
\hline Menores de $500 \mathrm{~h}$. & 74 \\
\hline Menores de $1000 \mathrm{~h}$. & 80 \\
\hline Entre 1000 y $25000 \mathrm{~h}$. & 93 \\
\hline Mayores de $25000 \mathrm{~h}$. & 100 \\
\hline
\end{tabular}




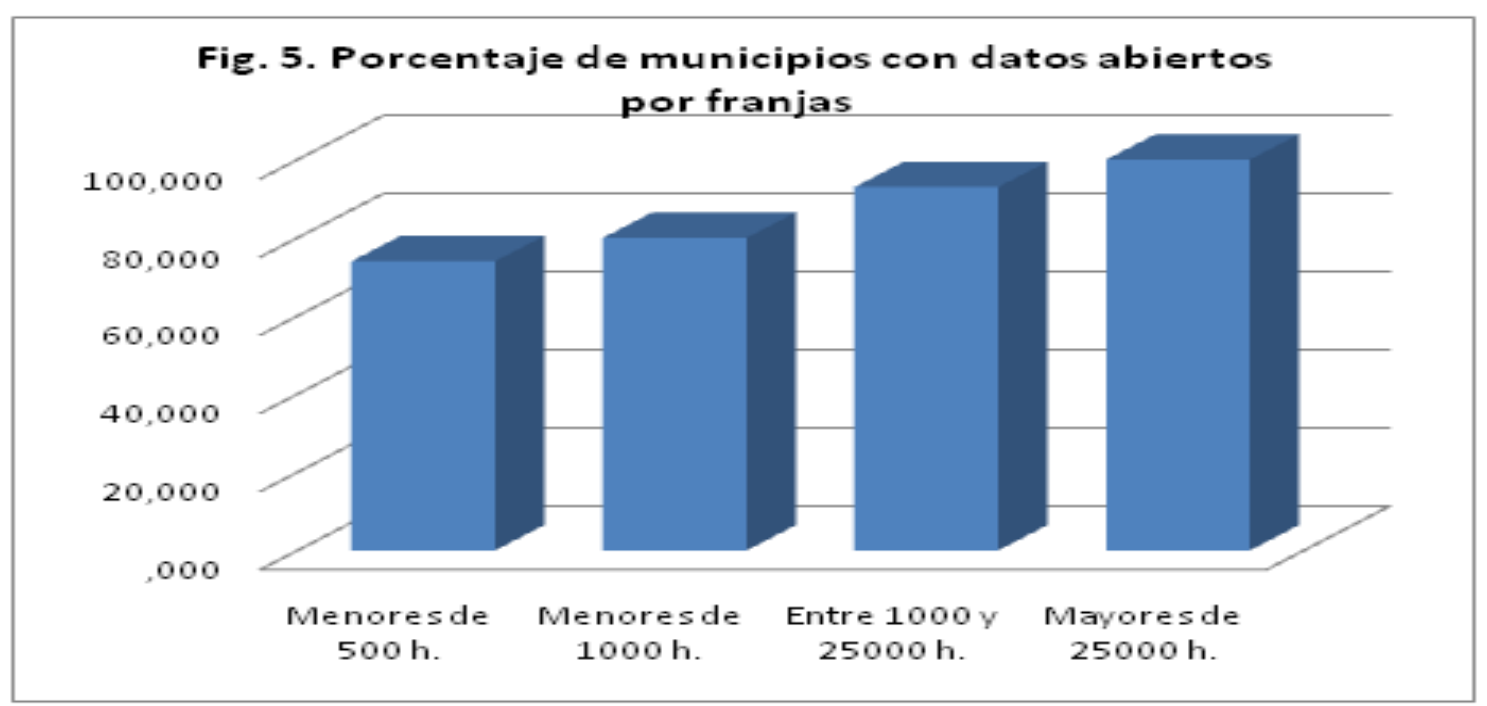

Es marcadamente significativo como a mayor número de habitantes por municipio el porcentaje de municipios que ofrecen algún tipo de datos abiertos en mayor, así entre los municipios menores de 500 habitantes el $74 \%$ de ellos ofrece datos abiertos, mientras que los municipios más grandes alcanzan la totalidad con el $100 \%$.

Si concretamos el análisis en aquellos temas en los que los municipios difunden sus datos en internet los porcentajes son más dispares. El primer caso lo podemos ver en la publicación de boletines, donde sólo la franja comprendida por los municipios medianos supera el 50\% que han incorporado en su web la edición de boletines de información municipal.

\begin{tabular}{|l|c|}
\hline \multicolumn{2}{|c|}{ Publicación de Boletines } \\
\hline \multicolumn{1}{|c|}{ Franja de municipios } & Porcentaje \\
\hline Menores de 500 h. & 6 \\
\hline Menores de 1000 h. & 19 \\
\hline Entre 1000 y 25000 h. & 55 \\
\hline Mayores de 25000 h. & 10 \\
\hline
\end{tabular}




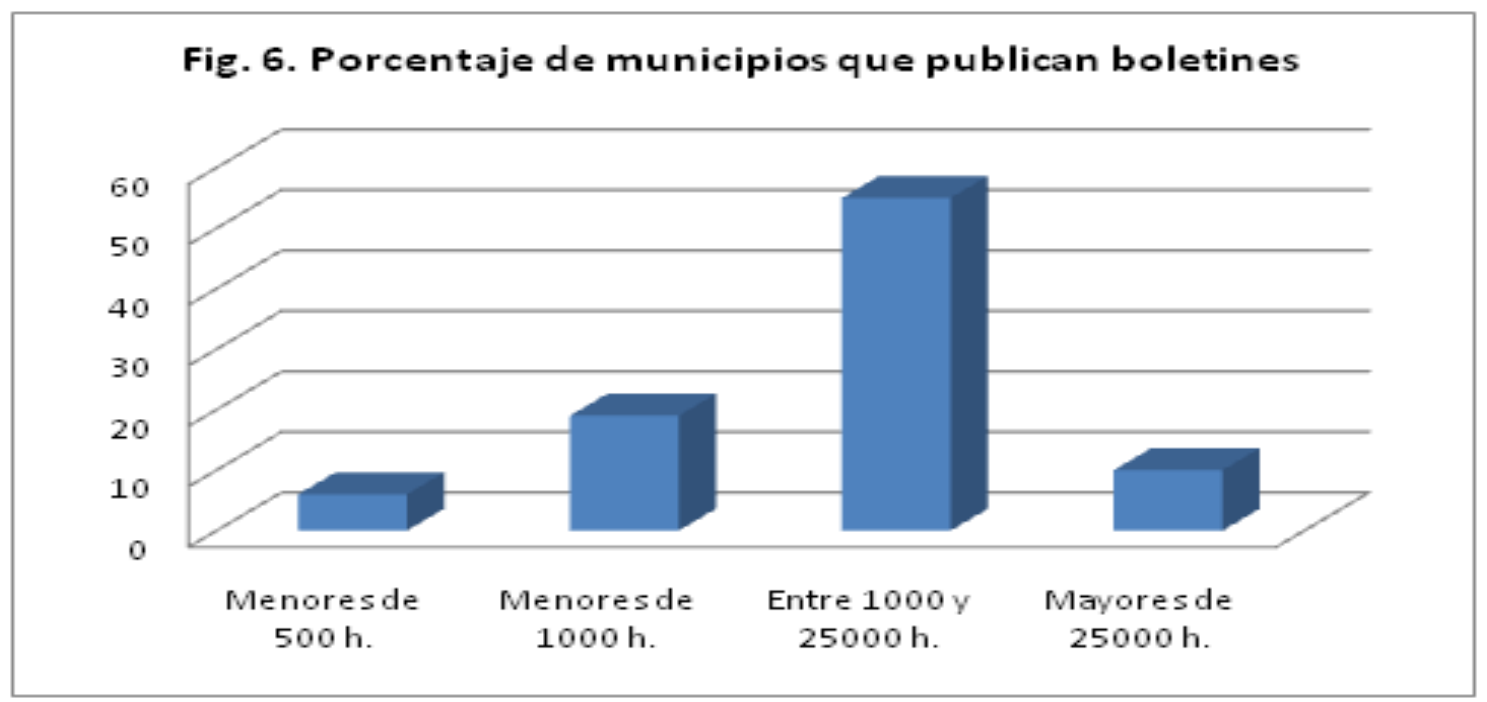

En general son escasos los municipios que utilizan la edición de boletines o periódicos para difundir sus actividades, incluso los mayores municipios, con más presupuesto, utilizan escasamente este recurso.

La publicación de las ordenanzas municipales por internet es uno de los que más se cumple, y todas las franjas de municipios superan el $50 \%$.

\begin{tabular}{|l|c|}
\hline \multicolumn{2}{|c|}{ Publicación de ordenanzas municipales } \\
\hline \multicolumn{1}{|c|}{ Franja de municipios } & Porcentaje \\
\hline Menores de $500 \mathrm{~h}$. & 52 \\
\hline Menores de $1000 \mathrm{~h}$. & 55 \\
\hline Entre 1000 y $25000 \mathrm{~h}$. & 65 \\
\hline Mayores de $25000 \mathrm{~h}$. & 84 \\
\hline
\end{tabular}

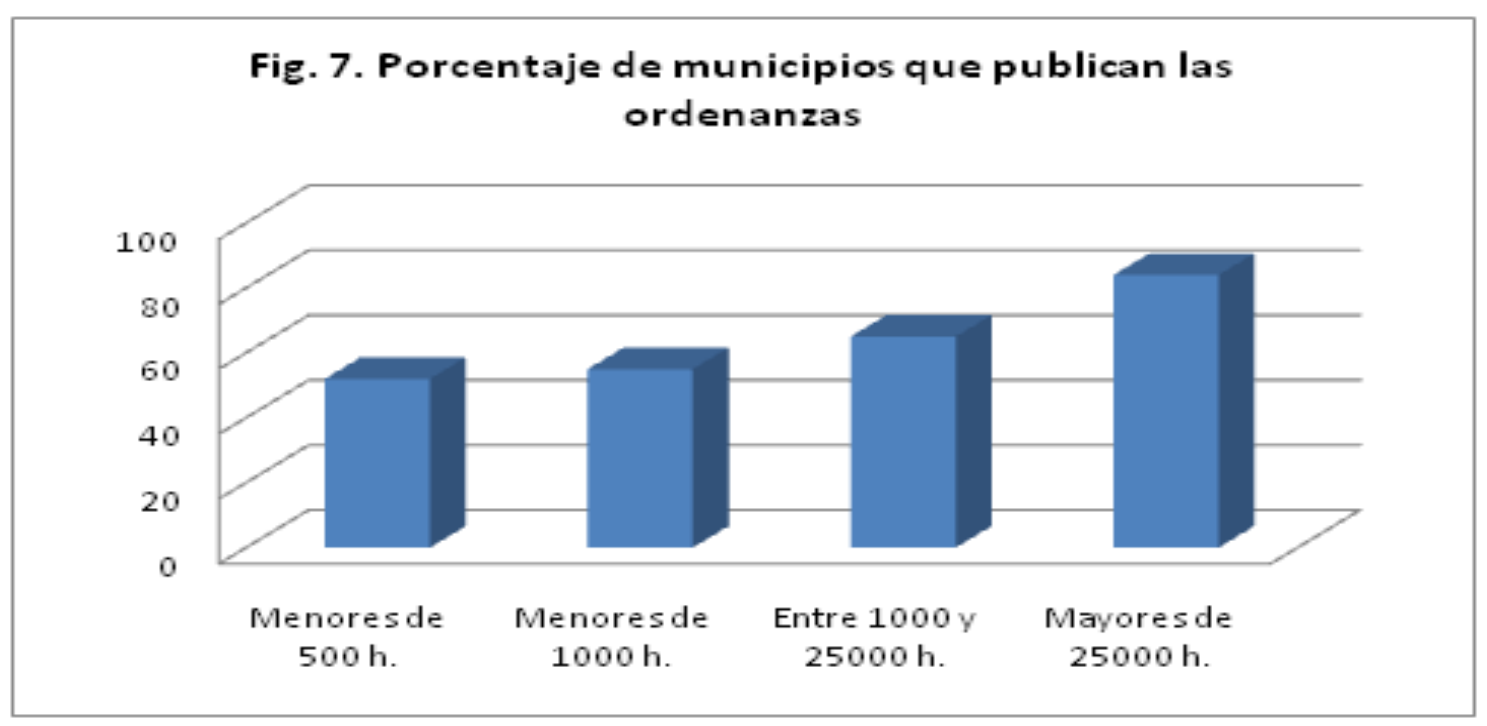


La mayoría de los municipios más grandes publican en internet las ordenanzas municipales (un 84\%), sin embrago la mayor parte de los municipios valencianos, dado que muchos son menores de 1000 habitantes, sólo las publican entre un $52 \%$ y un $65 \%$ de ellos. Aún así es uno de los temas más difundidos en los sitios web de los ayuntamientos.

Los bandos municipales se difunden escasamente por internet.

\begin{tabular}{|l|c|}
\hline \multicolumn{2}{|c|}{ Publicación de bandos municipales } \\
\hline \multicolumn{1}{|c|}{ Franja de municipios } & Porcentaje \\
\hline Menores de 500 h. & 6 \\
\hline Menores de 1000 h. & 10 \\
\hline Entre 1000 y 25000 h. & 25 \\
\hline Mayores de 25000 h. & 27 \\
\hline
\end{tabular}

Ni un tercio de los municipios más grandes de la Comunidad Valenciana alcanza a publicar los bandos por internet, y en los pequeños municipios es escasa su presencia.

Fig. 8. Porcentaje de municipios que publican los bandos

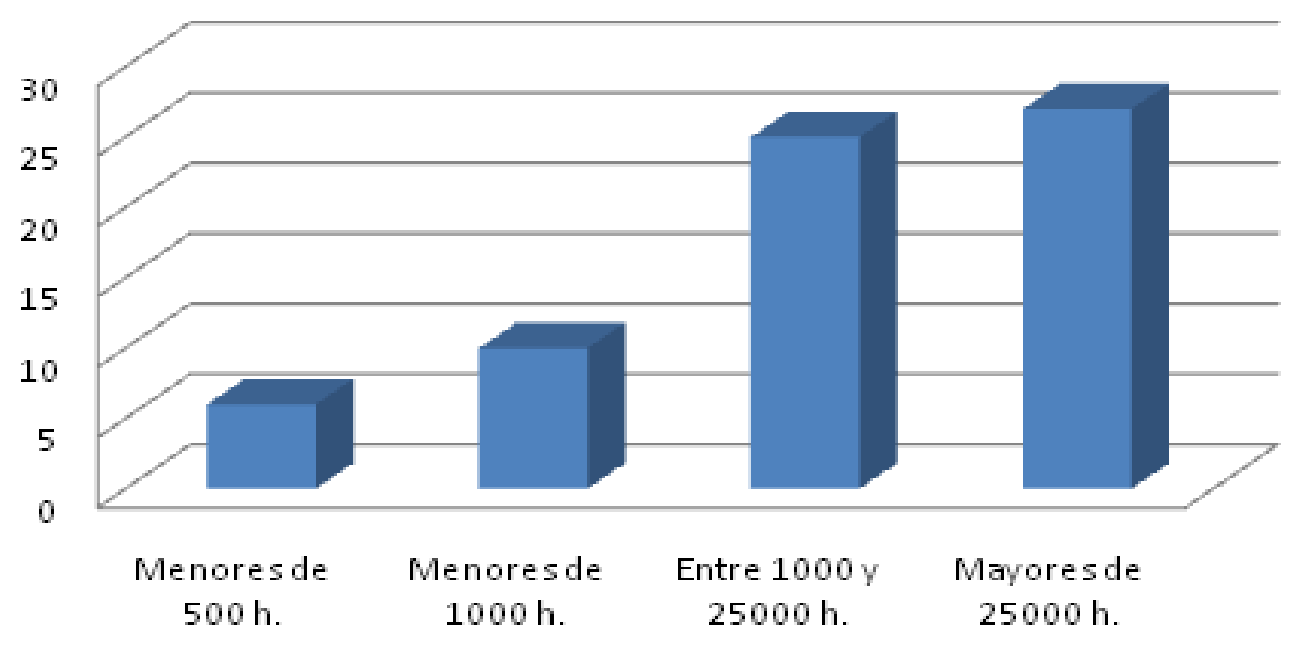


La publicación de estatutos o reglamentos es también es marcadamente escasa en los pequeños municipios.

\begin{tabular}{|l|c|}
\hline \multicolumn{2}{|c|}{ Publicación de estatutos y reglamentos } \\
\hline \multicolumn{1}{|c|}{ Franja de municipios } & Porcentaje \\
\hline Menores de $500 \mathrm{~h}$. & 6 \\
\hline Menores de $1000 \mathrm{~h}$. & 4 \\
\hline Entre 1000 y $25000 \mathrm{~h}$. & 13 \\
\hline Mayores de $25000 \mathrm{~h}$. & 44 \\
\hline
\end{tabular}

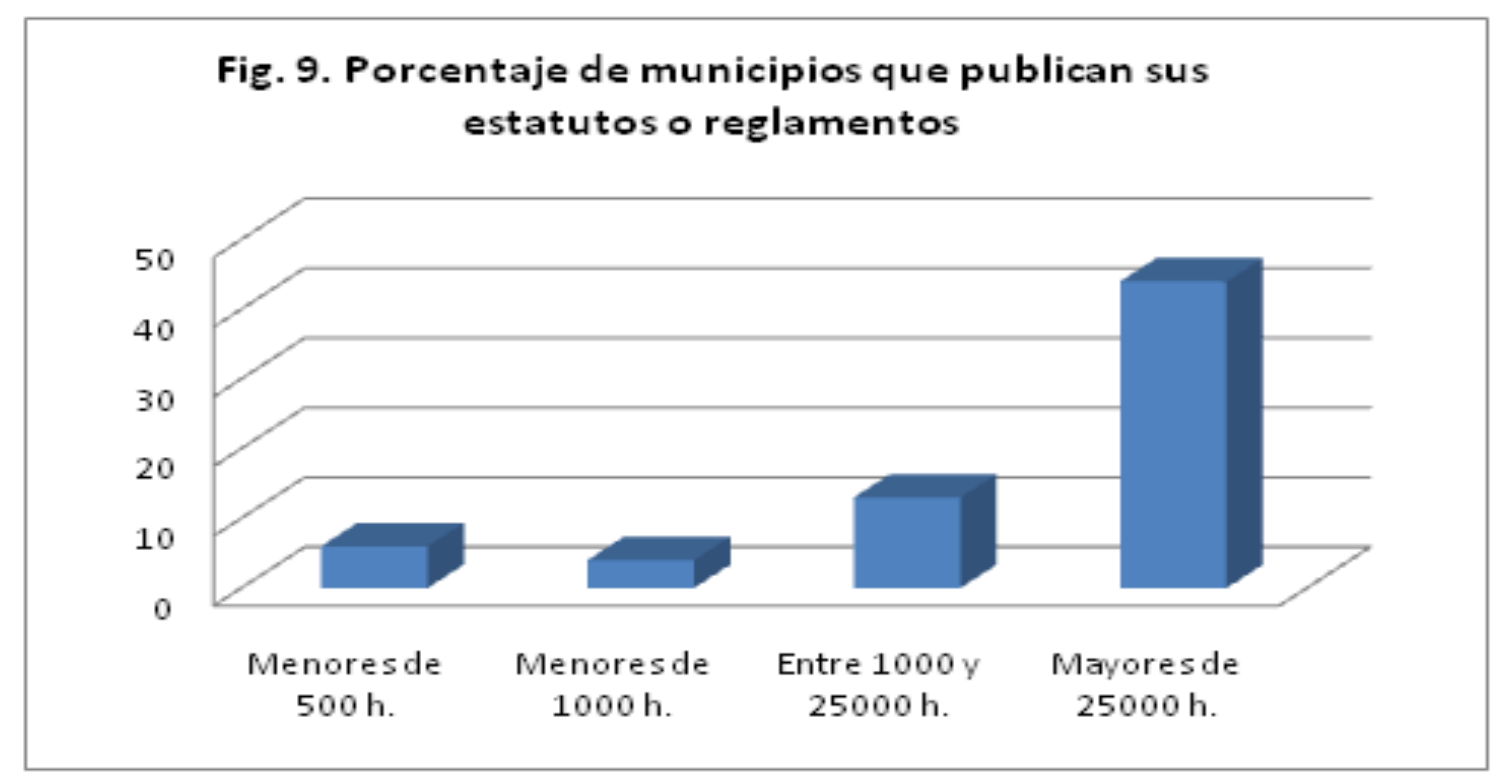

Solamente el $44 \%$ de los municipios más grandes difunden sus estatutos o reglamentos en su sitio web; el resto, con porcentajes que van del $4 \%$ al $13 \%$ no utilizan internet como forma de difundir sus reglamentos.

Las Juntas de Gobierno municipales también tienen una escasa difusión por internet.

\begin{tabular}{|l|c|}
\hline \multicolumn{2}{|c|}{ Publicación de las Juntas de Gobierno } \\
\hline \multicolumn{1}{|c|}{ Franja de municipios } & Porcentaje \\
\hline Menores de $500 \mathrm{~h}$. & 0 \\
\hline Menores de $1000 \mathrm{~h}$. & 1 \\
\hline Entre 1000 y $25000 \mathrm{~h}$. & 6 \\
\hline Mayores de $25000 \mathrm{~h}$. & 33 \\
\hline
\end{tabular}




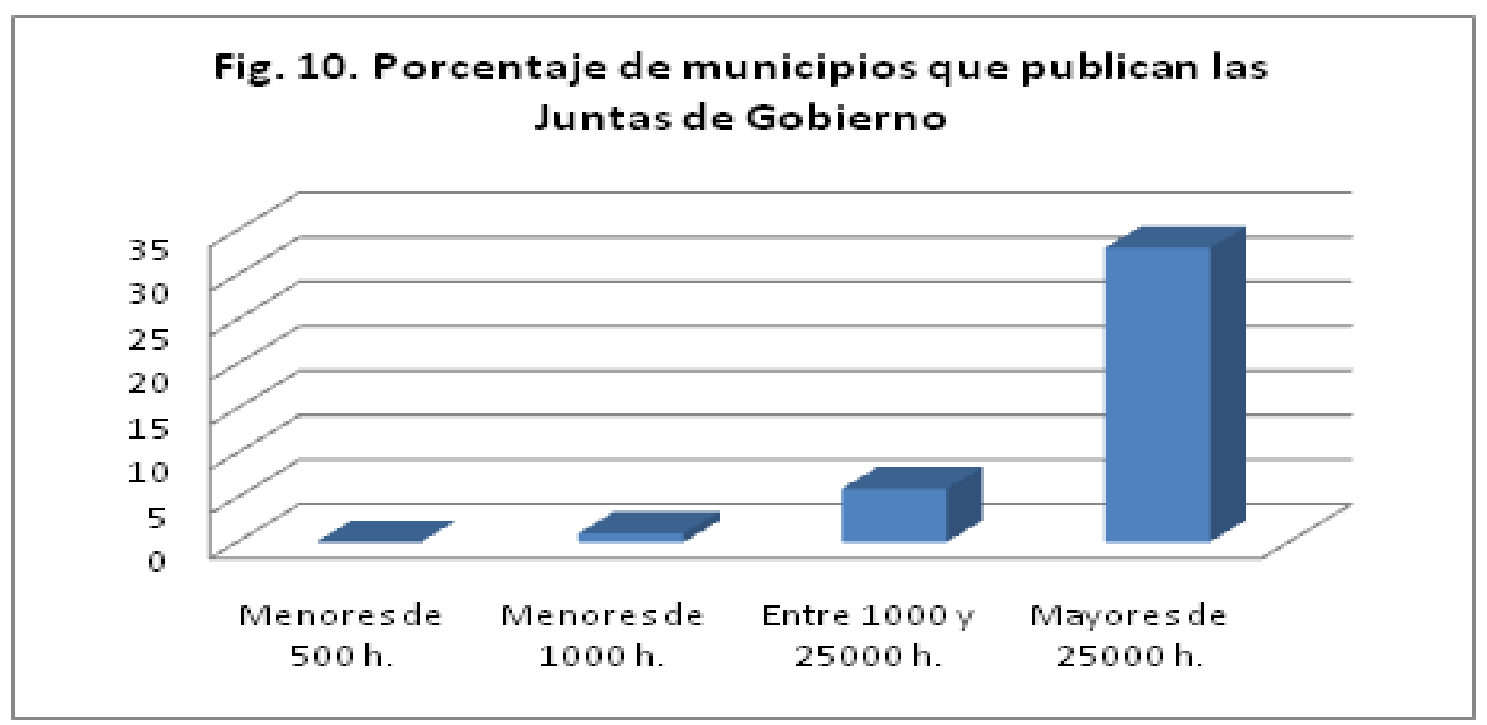

Claramente sólo algunos de los municipios más grandes, suponen el 33\% de ellos, publica las deliberaciones de las Juntas de Gobierno municipal en su sitio web. De los municipios menores de 500 habitantes no lo realiza ninguno, y del resto de municipios son muy pocos los que han optado por difundir las actas de las Juntas por internet.

Las actas de los plenos de los ayuntamientos se difunden más, pero de forma desigual en las distintas franjas de población de los municipios.

\begin{tabular}{|l|c|}
\hline \multicolumn{2}{|c|}{ Publicación de los Plenos } \\
\hline Franja de municipios & Porcentaje \\
\hline Menores de $500 \mathrm{~h}$. & 26 \\
\hline Menores de $1000 \mathrm{~h}$. & 28 \\
\hline Entre 1000 y $25000 \mathrm{~h}$. & 46 \\
\hline Mayores de $25000 \mathrm{~h}$. & 87 \\
\hline
\end{tabular}


MEI, II, Vol. 4, nº , pág. 145

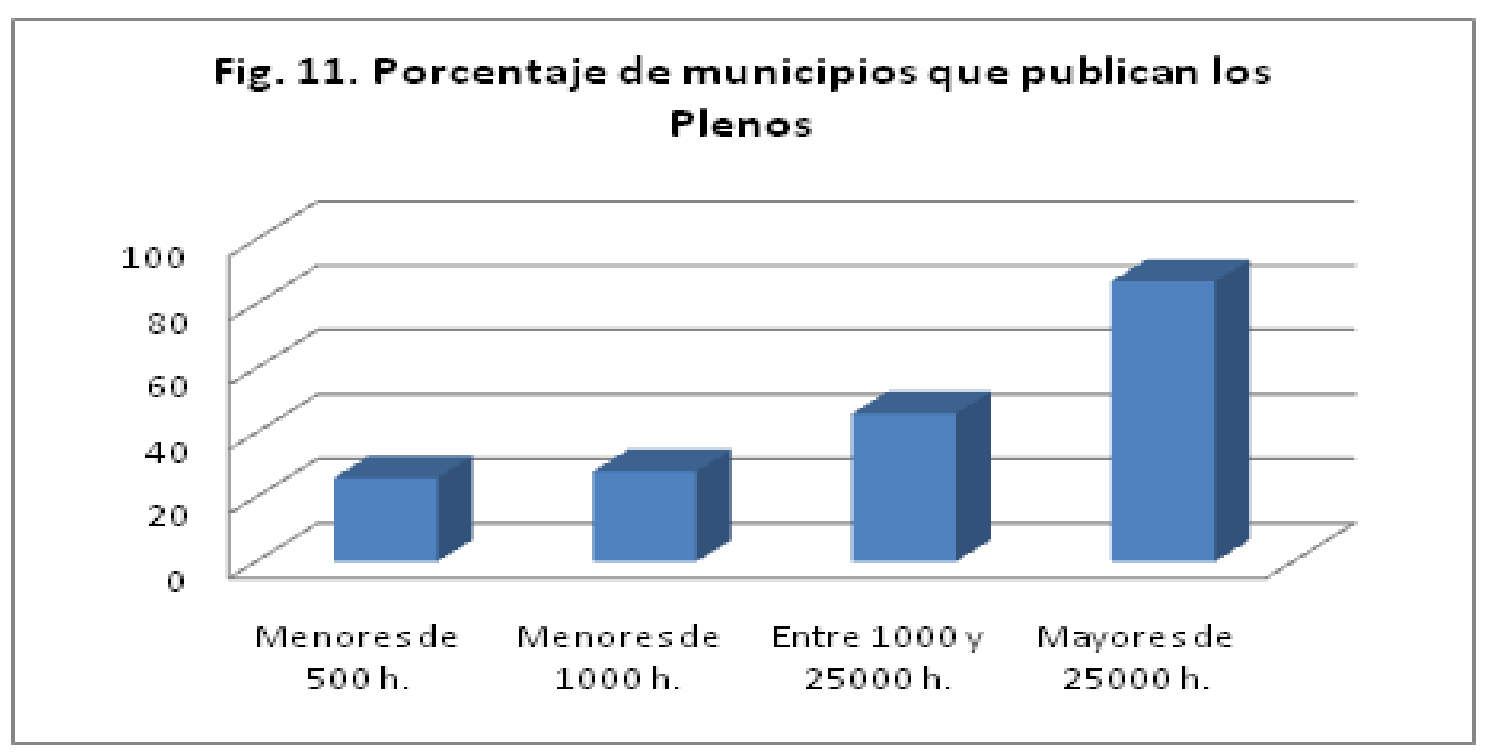

Solamente el $87 \%$ de los municipios más grandes publican sus plenos en internet. En los municipios medianos no llegan a la mitad los que han optado por difundir los plenos, y no llega a un tercio de los municipios pequeños. Es una baja práctica de gobierno abierto en un tema tan demandado por la sociedad, por la política de transparencia y buen gobierno.

La publicación de las retribuciones en los sitios web municipales es casi insignificante.

\begin{tabular}{|l|c|}
\hline \multicolumn{2}{|c|}{ Publicación de las retribuciones } \\
\hline \multicolumn{1}{|c|}{ Franja de municipios } & Porcentaje \\
\hline Menores de $500 \mathrm{~h}$. & 0 \\
\hline Menores de $1000 \mathrm{~h}$. & 0 \\
\hline Entre 1000 y $25000 \mathrm{~h}$. & 1 \\
\hline Mayores de $25000 \mathrm{~h}$. & 18 \\
\hline
\end{tabular}




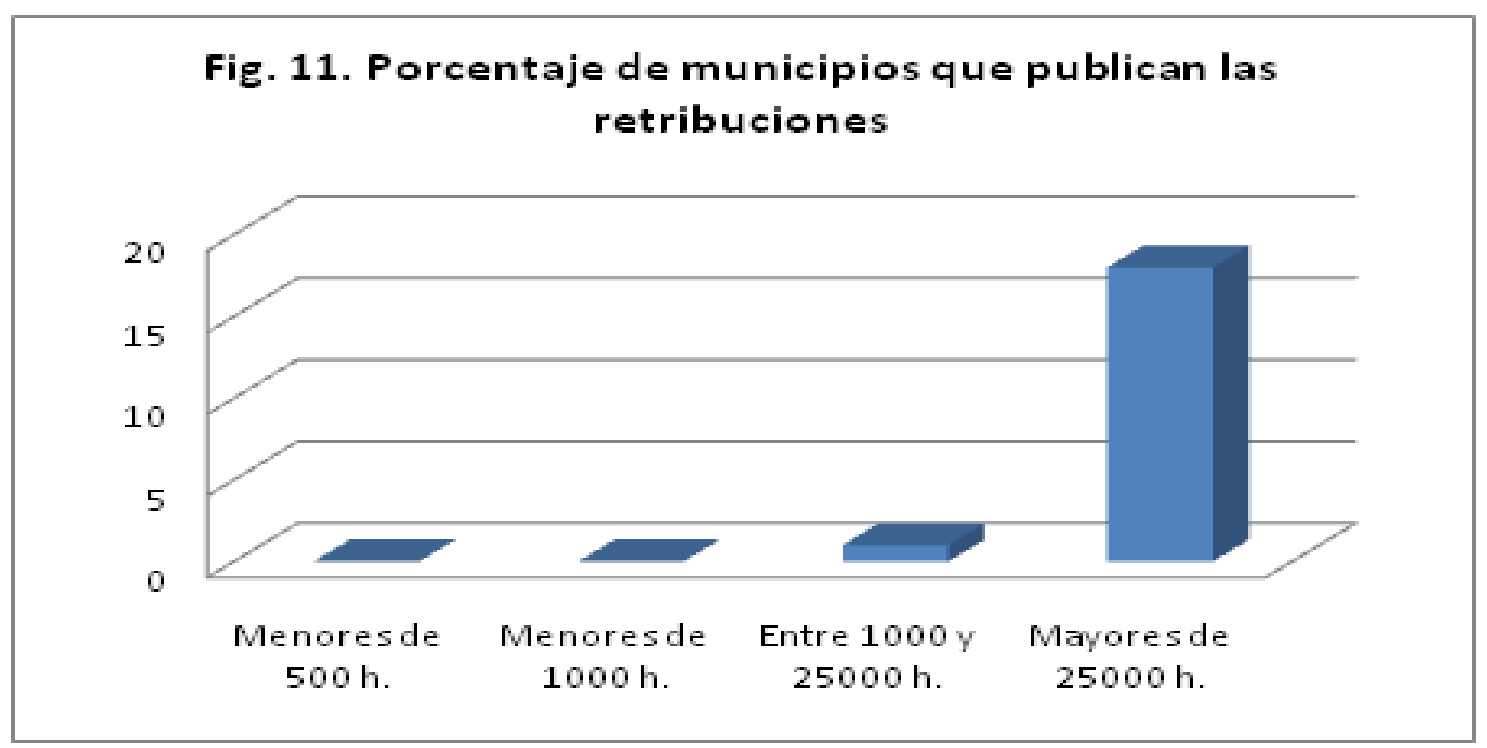

Ningún municipio menor de 1000 habitantes publica las retribuciones del equipo de gobierno municipal, y solamente el 1\% de los municipios medianos y el $18 \%$ de los municipios más grandes realizan un ejercicio de transparencia activa publicando las retribuciones de los gobernantes.

La publicidad del proceso de contratación de los servicios municipales igualmente es baja.

\begin{tabular}{|l|c|}
\hline \multicolumn{2}{|c|}{ Publicación de la contratación de servicios } \\
\hline \multicolumn{1}{|c|}{ Franja de municipios } & Porcentaje \\
\hline Menores de $500 \mathrm{~h}$. & 8 \\
\hline Menores de $1000 \mathrm{~h}$. & 14 \\
\hline Entre 1000 y $25000 \mathrm{~h}$. & 35 \\
\hline Mayores de $25000 \mathrm{~h}$. & 67 \\
\hline
\end{tabular}

Fig. 12. Porcentaje de municipios que publican la contratación de servicios

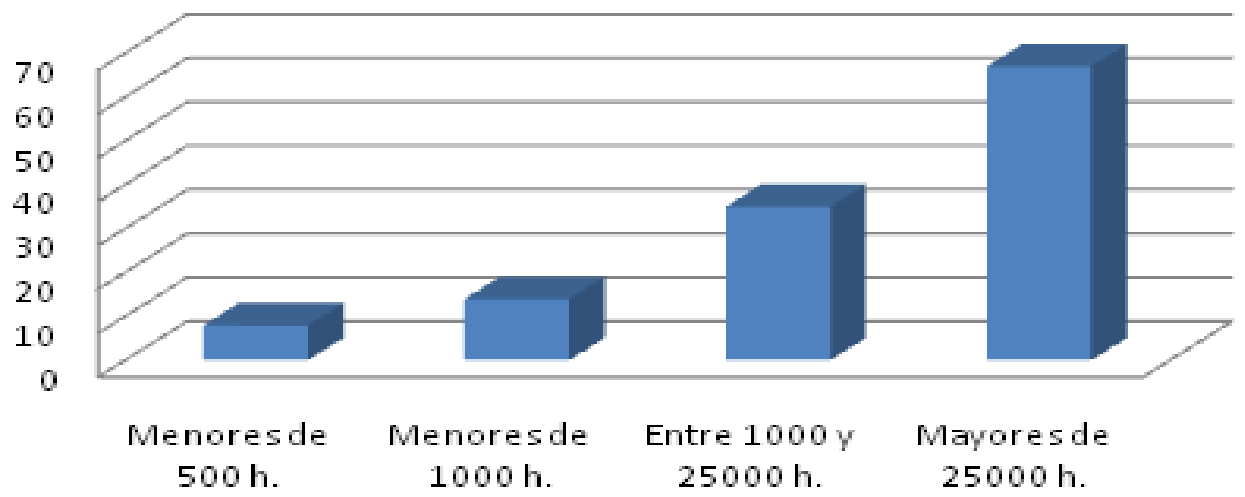


Solamente el 67\% de los grandes municipios publica el proceso de contratación de los servicios municipales, mientras que pocos de los municipios pequeños optan por esta difusión, y sólo un 35\% de los municipios medianos publica esta información en internet.

La publicación de los planes urbanísticos tiene una presencia relativa en todas las franjas de los municipios.

\begin{tabular}{|l|c|}
\hline \multicolumn{2}{|c|}{ Publicación de planes urbanísticos } \\
\hline \multicolumn{1}{|c|}{ Franja de municipios } & Porcentaje \\
\hline Menores de 500 h. & 24 \\
\hline Menores de 1000 h. & 27 \\
\hline Entre 1000 y 25000 h. & 36 \\
\hline Mayores de 25000 h. & 53 \\
\hline
\end{tabular}

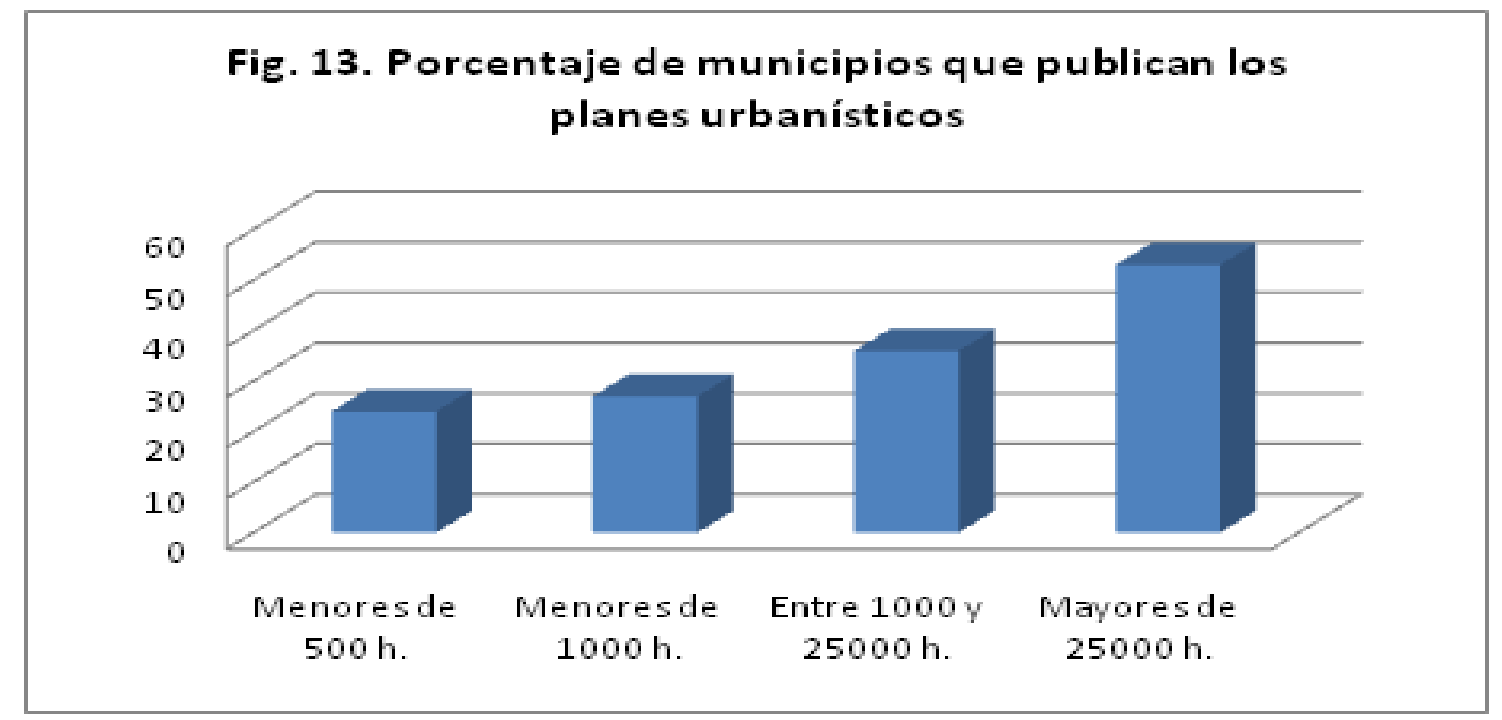

Sin embargo la particularidad es que en los municipios pequeños solamente entre un $24 \%$ y un $27 \%$ publican dichos planes, y en los municipios medianos aún sigue siendo bajo el porcentaje con sólo un 36\%. Sólo en los grandes municipios se alcanza un 53\% de los que optan por difundir la información urbanística. 
También son bajas las cifras de publicación de los presupuestos municipales.

\begin{tabular}{|l|c|}
\hline \multicolumn{2}{|c|}{ Publicación de los presupuestos municipales } \\
\hline Franja de municipios & Porcentaje \\
\hline Menores de $500 \mathrm{~h}$. & 29 \\
\hline Menores de $1000 \mathrm{~h}$. & 30 \\
\hline Entre 1000 y $25000 \mathrm{~h}$. & 51 \\
\hline Mayores de $25000 \mathrm{~h}$. & 22 \\
\hline
\end{tabular}

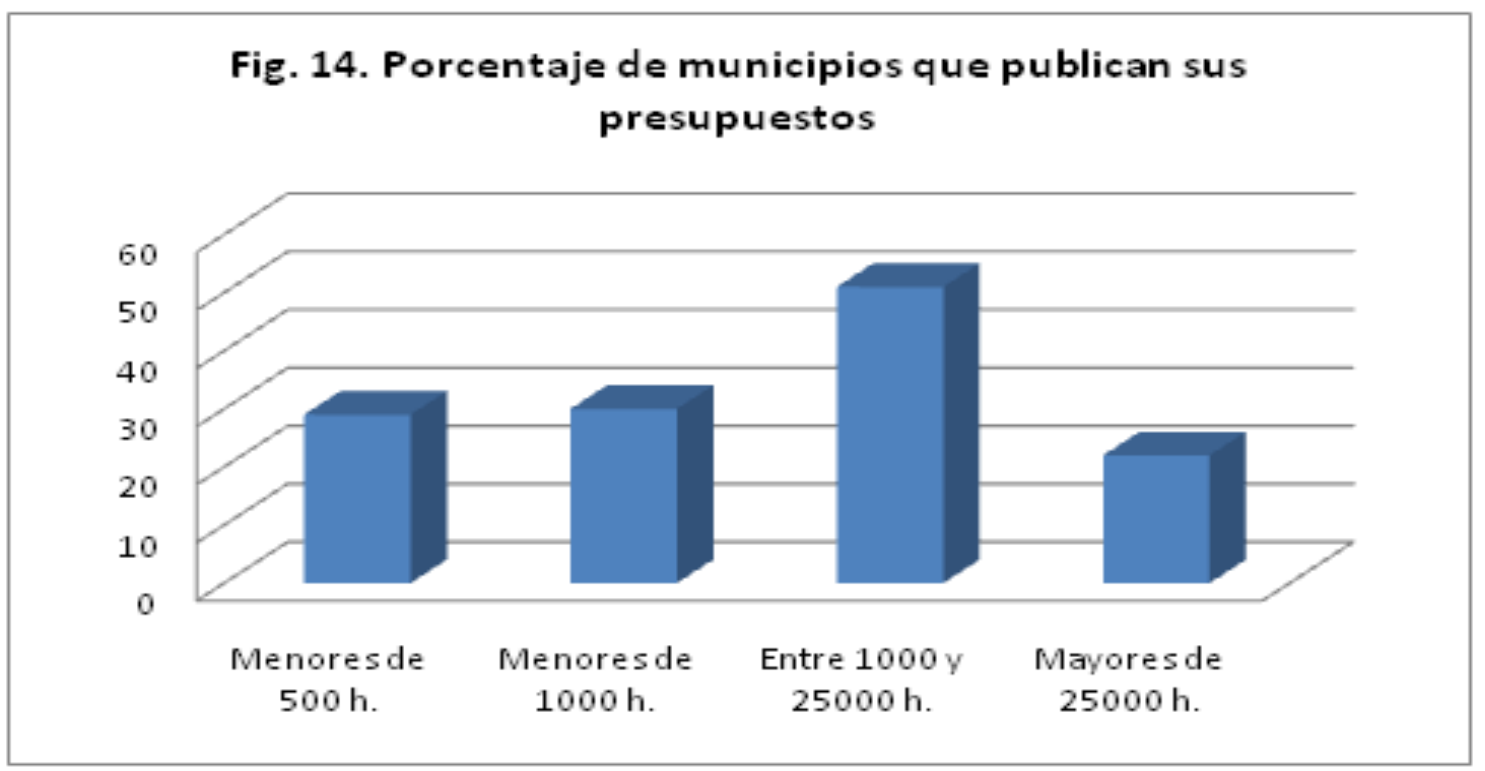

Si bien es cierto que muchos municipios utilizan el boletín oficial de la provincia para publicar sus presupuestos, es muy baja la opción de publicar los presupuestos en el sitio web del ayuntamiento. Sólo la mitad de los municipios medianos han optado por publicar estos datos (el 51\%), y destaca la singularidad, en este caso, de que los municipios más grandes tienen el porcentaje más bajo de los que publican sus presupuestos, en un $22 \%$. Los municipios pequeños lo hacen en cerca de una tercera parte. 


\section{4.-Distribución por partido político gobernante.}

Por otro lado, también se ha estudiado la relación entre el nivel de datos abiertos y el partido gobernante. Tal como puede observarse en la Fig. 15, el panorama político local de la Comunitat Valenciana está dominado por el Partido Popular que gobierna en 354 municipios. Le sigue, a cierta distancia el PSOE, con 135 localidades. Muy minoritarias siguen siendo otras opciones como Bloc-Compromís con 22 alcaldías o Esquerra Unida, con 5.

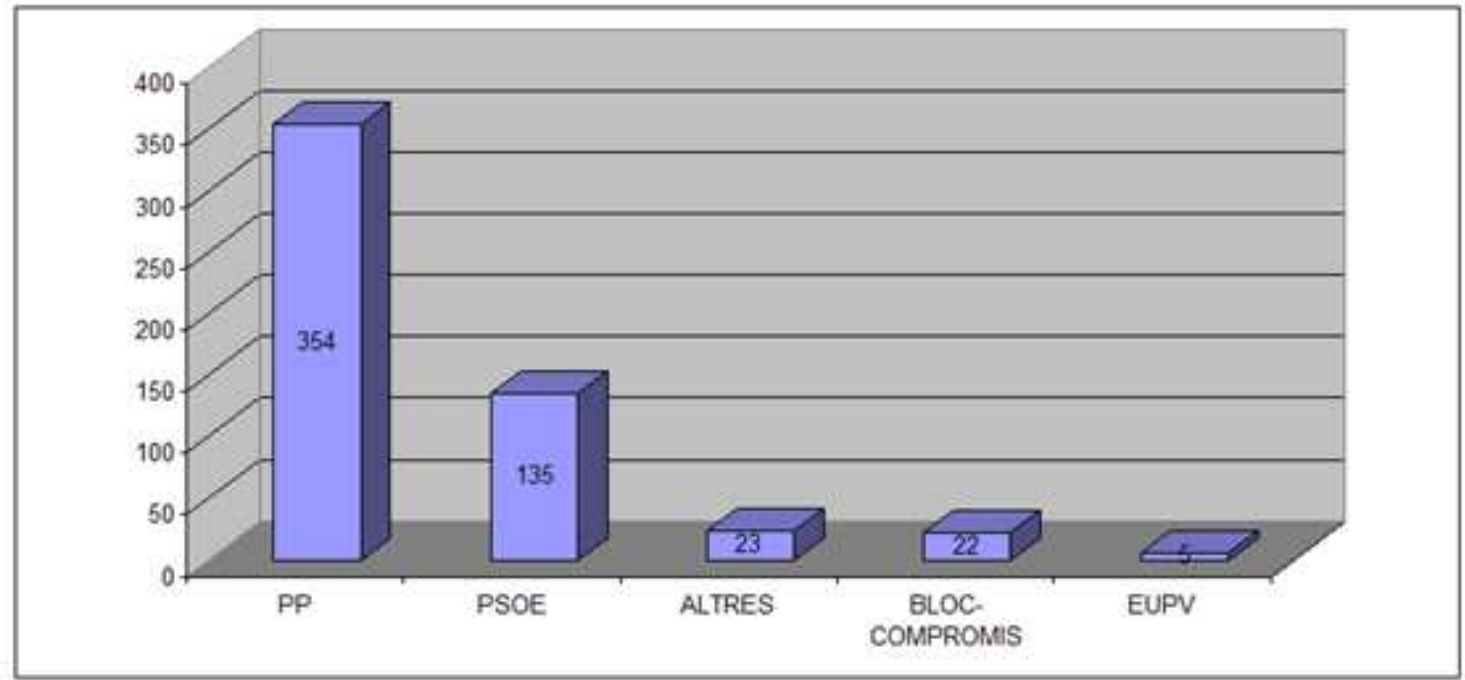

FIG 15. Municipios según partido político gobernante en la Comunitat Valenciana (2013)

\section{5.-Ranking de municipios en gobierno abierto}

Se han seleccionado como los principales municipios que ejercen un gobierno abierto a aquellos que cumplen como criterio ofrecer más de 6 temas en datos abiertos. Estos los valoramos como los primeros en un ranking de valoración. De los 542 municipios de la Comunidad Valenciana solamente cumplen esta condición 32 de ellos. En la siguiente tabla podemos ver el listado de los mismos. 
Tabla 2: Municipios que ofrecen más de 6 temas en datos abiertos

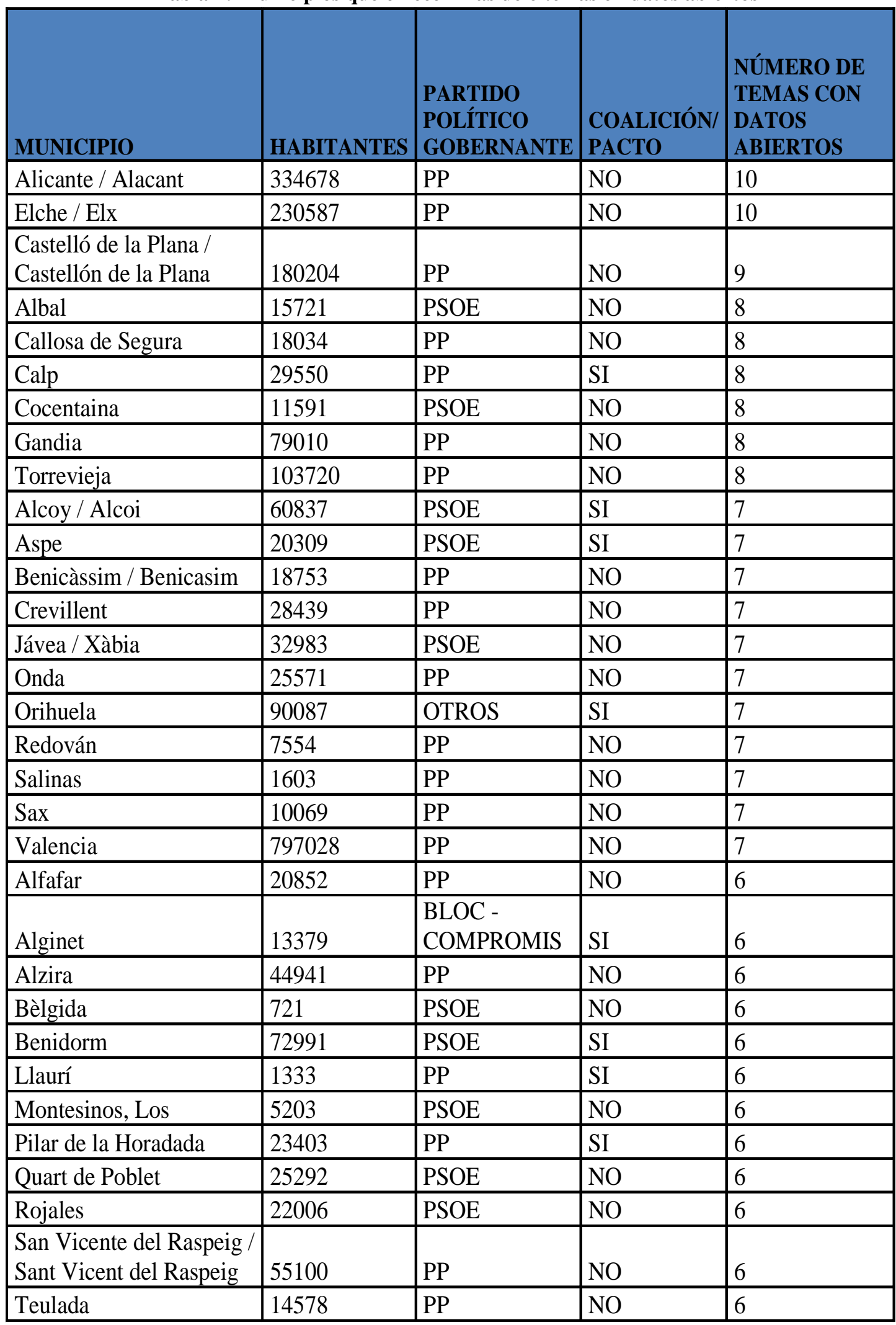


Estos datos reflejan un predominio de los gobiernos por un partido único, el partido que detenta la alcaldía. De los 32 municipios 8 gobiernan en coalición o han realizado algún tipo de pacto.

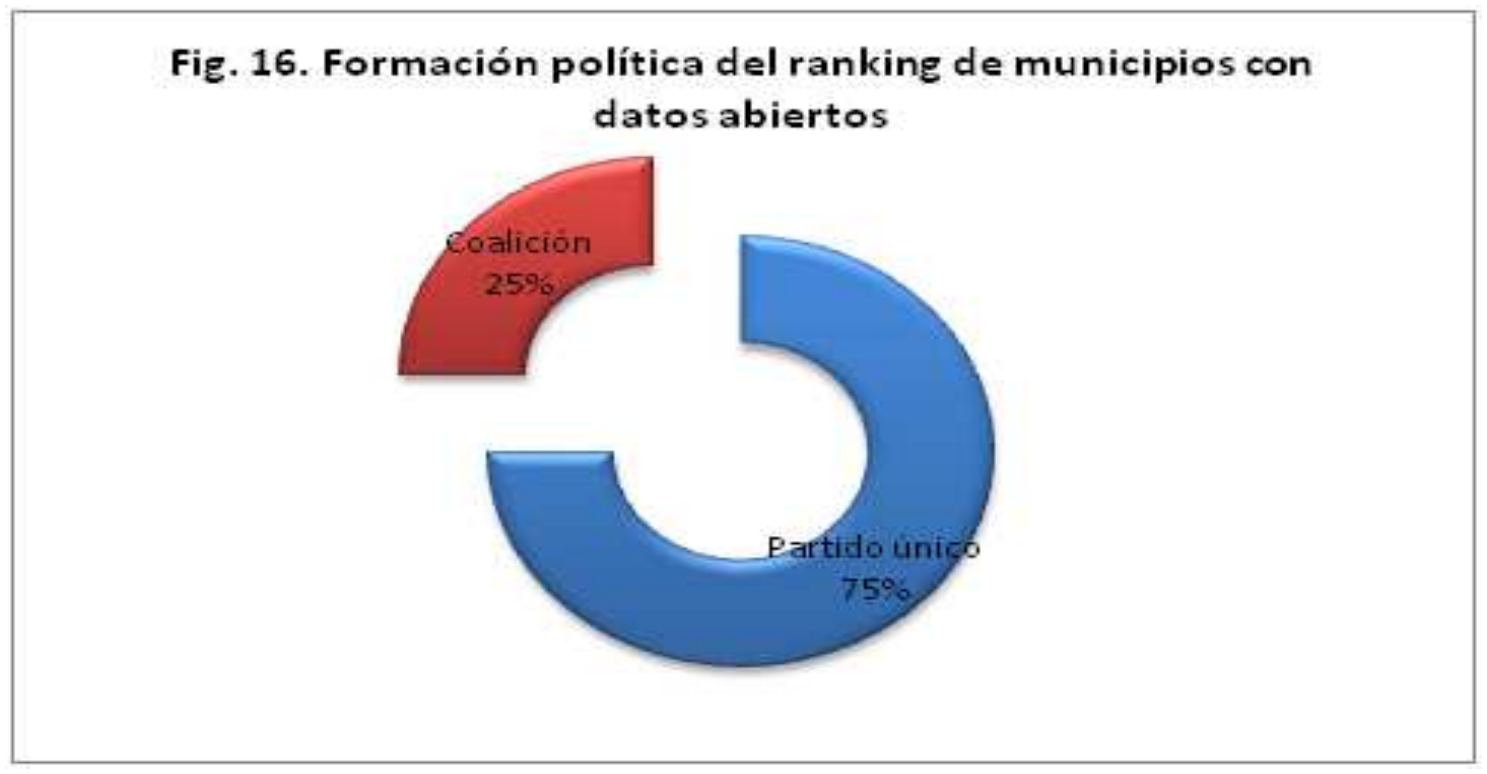

Tras las últimas elecciones municipales de 2011 donde el Partido Popular obtuvo la mayoría de los municipios en la Comunidad Valenciana, la presencia de este en el ranking es manifiesta. De los 32 municipios, en 20 la alcaldía pertenece al Partido Popular y en 10 al Partido Socialista Obrero Español, aunque, como hemos mencionado, muchos de ellos gobiernan en coalición con otros partidos para obtener la mayoría absoluta.

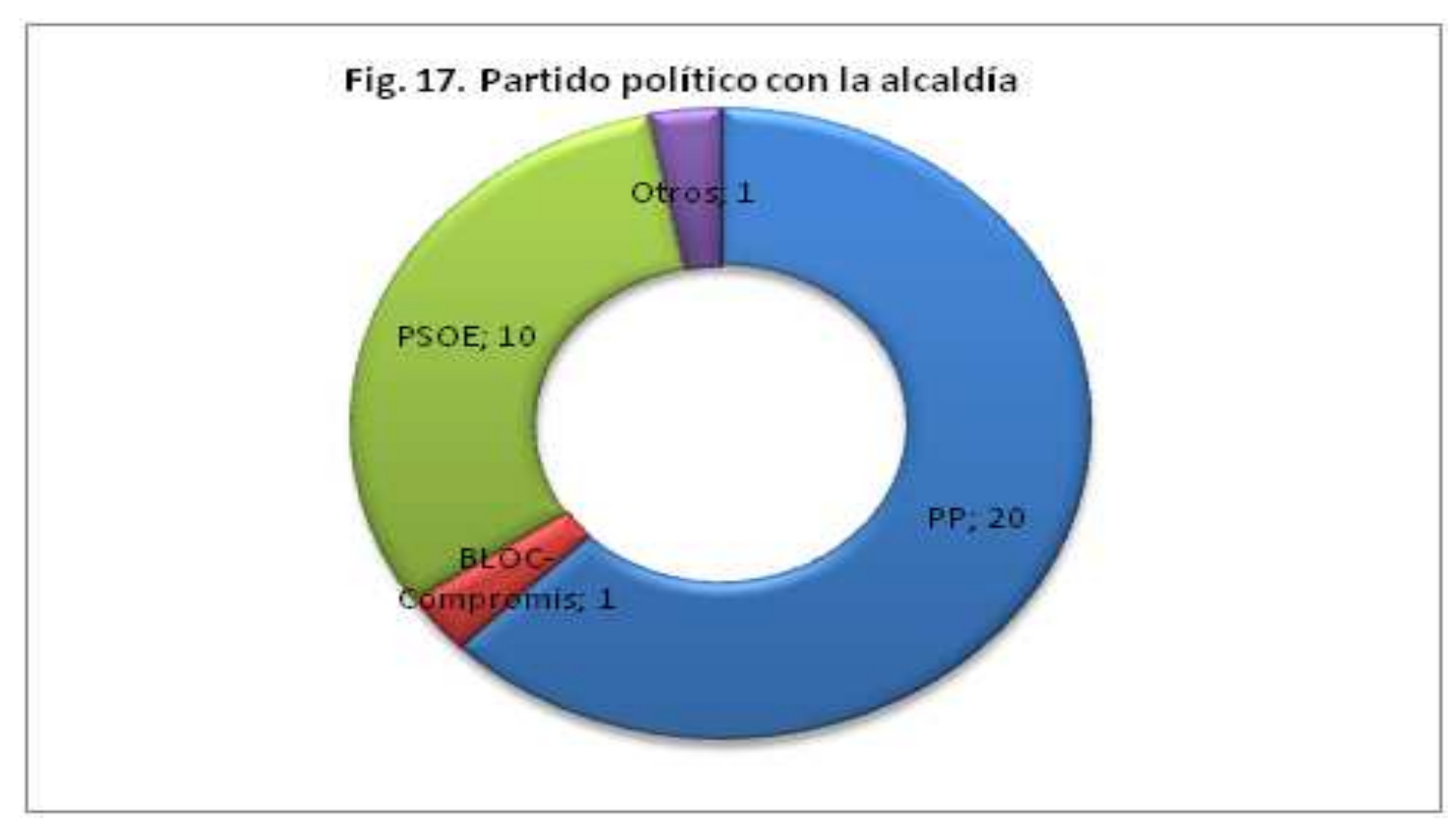


MEI, II, Vol. 4, nº , pág. 152

El número de habitantes no determina la preeminencia de los municipios a la hora de ofrecer datos abiertos, de forma que nos podemos encontrar con los municipios más grandes, como la ciudad de Valencia, o con los más pequeños como Bèlgida o Llaurí.

\section{4.- Conclusiones}

La mayor parte de los municipios valencianos presentan algún tipo de información de su gobierno en el sitio web del ayuntamiento, un $89 \%$ de los municipios. Sin embargo un análisis más detallado deja patente una disparidad en el ejercicio de esta práctica por los gobiernos locales, desde los que solamente publicitan un tipo de información hasta los que alcanzan a difundir diez tipos de información (sólo dos ayuntamientos).

Los temas en los cuales los ayuntamientos más se preocupan en difundir sus responsabilidades de gobierno son la publicación de las Ordenanzas y de las actas de los Plenos. En contra, lo que menos publicitan son las retribuciones del equipo de gobierno y las actas de las Juntas de Gobierno. Los Boletines de Información Municipal, a pesar de ser un medio idóneo para difundir las actividades del ayuntamiento, están bastante infrautilizados, reflejando el escaso interés de muchos municipios en la práctica de un verdadero gobierno abierto.

En general los municipios más grandes son los que más información difunden de su gobierno, en el contexto general de que los tipos de información o temas difundidos es muy baja, dado que sólo figuran porcentajes altos en los temas de Ordenanzas y Plenos. Solamente hay una excepción en la que los municipios más grandes difunden menos, es en el caso de publicar los presupuestos, donde los municipios menores y medianos superan a los grandes.

\section{5.- Bibliografía}

Chandler, Helen E. (1998) Towards open government: official information on the Web, New Library World, Vol. 99 Iss: 6, pp.230 - 237. DOI: 10.1108/03074809810236784

Franch Auladell, X.; Marti-Henneberg, Jordi; Puig-Farré, J. (2013). Un análisis espacial de las pautas de crecimiento y concentración de la población a partir de series homogéneas: España (1877-2001), Investigaciones regionales, $\mathrm{n}^{\circ} 25$, pp. 43-65

Giménez-Chornet, Vicent (2012) Acceso de los ciudadanos a los documentos como transparencia de la gestión pública. El profesional de la información, septiembre-octubre, v. 21, n. 5, pp. 504-508. DOI: http://dx.doi.org/10.3145/epi.2012.sep.09

Kierkegaard, Sylvia (2009), Open access to public documents - More secrecy, less transparency!, Computer Law \& Security Review, Volume 25, Issue 1, pp. 3-27. DOI: http://dx.doi.org/10.1016/ j.clsr.2008.12.001

Membrado Tena, J. C. (2013). La división territorial valenciana: antecedentes, problemas y política de la Generalitat, Investigaciones Geográficas, $\mathrm{n}^{\circ}$ 59, enero - junio, pp. 05-24, DOI: 10.14198/ INGEO2013.59.01 
MEI, II, Vol. 4, nº , pág. 153

Reddick, Christopher G. (2011) Citizen interaction and e-government: Evidence for the managerial, consultative, and participatory models, Transforming Government: People, Process and Policy, Vol. 5 Iss: 2 , pp. $167-184$. DOI: 10.1 108/17506161111131195

Unión Europea (2003) Directiva 2003/98/CE del Parlamento Europeo y del Consejo, de 17 de noviembre de 2003, relativa a la reutilización de la información del sector público Diario Oficial $n^{\circ} \mathrm{L}$ 345 de 31/12/2003 pp. 0090-0096. Disponible en: http://eur-lex.europa.eu/LexUriServ/ LexUriServ.do?uri=CELEX:32003L0098:ES:HTML

Vercelli, Ariel (2010) Datos, informaciones, obras y gobiernos abiertos a los ciudadanos, Open

Government: Gobierno Abierto. Jaen: Algón Editores, pp. 251-265

\section{6.- Notas}

1.- Los participantes en el proyecto inicial de creación del portal web, además de los dos profesores (Vicent Giménez Chornet y Miguel Carlos Muñoz Feliu) fueron un total de nueve alumnos: Pilar Alemany Martínez, Daniel Català Pérez, Víctor Fernández Santos, Immaculada Luz Collado, Natividad Romina Masciotta, M Ángeles Royo Zurriaga, José Ricardo Salavert Griñón, $M^{a}$ Luz Ureña González, Andrés Valero Panadero 